\title{
Chapter 5 \\ Seismic Code Developments for Steel and Composite Structures
}

\author{
Ahmed Y. Elghazouli
}

\begin{abstract}
As with other codified guidance, seismic design requirements undergo a process of continuous evolution and development. This process is usually guided by improved understanding of structural behaviour based on new research findings, coupled with the need to address issues identified from the practical application of code procedures in real engineering projects. Developments in design guidance however need to balance detailed technical advancements with the desire to maintain a level of practical stability and simplicity in codified rules. As a result, design procedures inevitably incorporate various simplifications and idealisations which can in some cases have adverse implications on the expected seismic performance and hence on the rationale and reliability of the design approaches. With a view to identifying the needs for future seismic code developments, this paper focuses on assessing the underlying approaches and main procedures adopted in the seismic design of steel and composite framed structures, with emphasis on the current European seismic design code, Eurocode 8. Codified requirements in terms of force reduction factors, ductility considerations, capacity design verifications, and connection design procedures, are examined. Various requirements that differ notably from other international seismic codes, particularly those incorporated in North American provisions, are also pointed out. The paper highlights various issues related to the seismic design of steel and composite frames that can result in uneconomical or impractical solutions, and outlines several specific seismic code development needs.
\end{abstract}

\subsection{Introduction}

Steel and composite steel/concrete structures may be designed based on EC8 (Eurocode 8 2005) according to either non-dissipative or dissipative behaviour. The former is normally limited to areas of low seismicity or to structures of special

\footnotetext{
A.Y. Elghazouli $(\varangle)$

Department of Civil and Environmental Engineering, Imperial College London, London, UK

e-mail: a.elghazouli@imperial.ac.uk
}

A. Ansal (ed.), Perspectives on European Earthquake Engineering and Seismology, Geotechnical, Geological and Earthquake Engineering 39,

DOI 10.1007/978-3-319-16964-4_5 
use and importance, although it could also be applied for higher seismicity areas if vibration reduction or isolation devices are incorporated. Otherwise, the code aims to achieve economical design by employing dissipative behaviour which, apart from for special irregular or complex structures, is usually performed by assigning a structural behaviour factor to reduce the code-specified forces resulting from idealised elastic response spectra. This is carried out in conjunction with the capacity design concept which requires an appropriate determination of the capacity of the structure based on a pre-defined plastic mechanism, coupled with the provision of sufficient ductility in plastic zones and adequate over-strength factors for other regions.

This paper examines the dissipative seismic design provisions for steel and composite framed structures, which are mainly covered in Part 1 (general rules, seismic actions and rules for buildings) of Eurocode 8 (2005). General provisions in other sections of EC8 Part 1 are also referred to where relevant. Additionally, where pertinent, reference is made to US procedures for the seismic design of steel and composite structures (ASCE7 2010; AISC341 2010). The assessment focuses on the behaviour factors, ductility considerations, capacity design rules and connection design requirements stipulated in EC8. Particular issues that warrant clarification or further developments are highlighted and discussed.

\subsection{Behaviour Factors}

EC8 focuses essentially on three main structural steel frame systems, namely moment resisting, concentrically braced and eccentrically braced frames. Other systems such as hybrid and dual configurations are referred to in EC8, but limited information is provided. It should also be noted that additional configurations such as those incorporating buckling restrained braces, truss moment frames or special plate shear walls, which are covered in recent US provisions, are not directly addressed in the current version of EC8.

The behaviour factors are typically recommended by codes of practice based on background research involving extensive analytical and experimental investigations. The reference behaviour factors $(q)$ stipulated in EC8 for steel-framed structures are summarised in Table 5.1. These are upper values of $q$ allowed for each system, provided that regularity criteria and capacity design requirements are met. For each system, the dissipative zones are specified in the code (e.g. beam ends, diagonals, link zones in moment, concentrically braced and eccentrically braced frames, respectively). The multiplier $\alpha_{u} / \alpha_{1}$ depends on the failure/first plasticity resistance ratio of the structure, and can be obtained from push-over analysis (but should not exceed 1.6). Alternatively, default code values can be used to determine $q$ (as given in parenthesis in Table 5.1). 
Table 5.1 Behaviour factors in European and US Provisions

\begin{tabular}{|c|c|c|c|}
\hline European Provisions & Ductility class & q & $q_{d}$ \\
\hline Non-dissipative & DCL & 1.5 & 1.5 \\
\hline \multirow[t]{2}{*}{ Moment frames } & DCM & 4.0 & 4.0 \\
\hline & $\mathrm{DCH}$ & $\begin{array}{l}5 \alpha_{\mathrm{u}} / \alpha_{1} \\
(5.5-6.5)\end{array}$ & $\begin{array}{l}5 \alpha_{\mathrm{u}} / \alpha_{1} \\
(5.5-6.5)\end{array}$ \\
\hline \multirow[t]{2}{*}{ Concentric braced } & DCM & 4.0 & 4.0 \\
\hline & $\mathrm{DCH}$ & 4.0 & 4.0 \\
\hline \multirow[t]{2}{*}{ V-braced } & DCM & 2.0 & 2.0 \\
\hline & $\mathrm{DCH}$ & 2.5 & 2.5 \\
\hline \multirow[t]{2}{*}{ Eccentrically braced } & DCM & 4.0 & 4.0 \\
\hline & $\mathrm{DCH}$ & $5 \alpha_{\mathrm{u}} / \alpha_{1}(6.0)$ & $5 \alpha_{u} / \alpha_{1}(6.0)$ \\
\hline \multirow{2}{*}{$\begin{array}{l}\text { Dual moment-concentric } \\
\text { braced }\end{array}$} & DCM & 4.0 & 4.0 \\
\hline & $\mathrm{DCH}$ & $4 \alpha_{\mathrm{u}} / \alpha_{1}(4.8)$ & $4 \alpha_{u} / \alpha_{1}(4.8)$ \\
\hline US Provisions & Frame type & $\mathbf{R}$ & $\mathbf{C}_{\mathrm{d}}$ \\
\hline Non-dissipative & Non-seismic detailing & 3.0 & 3.0 \\
\hline \multirow[t]{3}{*}{ Moment frames (steel) } & OMF & 3.5 & 3.0 \\
\hline & IMF & 4.5 & 4.0 \\
\hline & SMF & 8.0 & 5.5 \\
\hline \multirow[t]{4}{*}{ Moment frames (composite) } & $\mathrm{C}-\mathrm{OMF}$ & 3.0 & 2.5 \\
\hline & C-IMF & 5.0 & 4.5 \\
\hline & C-SMF & 8.0 & 5.5 \\
\hline & C-PRMF & 6.0 & 5.5 \\
\hline \multirow[t]{2}{*}{ Concentric braced (steel) } & OSCBF & 5.0 & 4.5 \\
\hline & SSCBF & 6.0 & 5.0 \\
\hline \multirow[t]{2}{*}{ Concentric braced (composite) } & $\mathrm{C}-\mathrm{OCBF}$ & 3.0 & 3.0 \\
\hline & C-SCBF & 5.0 & 4.5 \\
\hline \multirow[t]{2}{*}{ Eccentrically braced } & $\mathrm{EBF}\left(\mathrm{MC}^{\mathrm{a}}\right)$ & 8.0 & 4.0 \\
\hline & $\mathrm{EBF}\left(\right.$ non-MC $\left.\mathrm{M}^{\mathrm{a}}\right)$ & 7.0 & 4.0 \\
\hline $\begin{array}{l}\text { Eccentrically braced } \\
\text { (composite) }\end{array}$ & C-EBF & 8.0 & 4.0 \\
\hline Dual moment-braced & $\begin{array}{l}\text { Various detailed } \\
\text { systems }\end{array}$ & $4.0-8.0$ & $3.0-6.5$ \\
\hline
\end{tabular}

${ }^{\mathrm{a}} \mathrm{MC}$ refers to moment beam-to-column connections away from the links

The same upper limits of the reference behaviour factors specified in EC8 for steel framed structures are also employed for composite structures. This applies to composite moment resisting frames, composite concentrically braced frames and composite eccentrically braced frames. However, a number of additional composite structural systems are also specified, namely: steel or composite frames with connected infill concrete panels, reinforced concrete walls with embedded vertical steel members acting as boundary/edge elements, steel or composite coupling beams in conjunction with reinforced concrete or composite steel/concrete walls, and composite steel plate shear walls. These additional systems are beyond the scope of the discussions in this paper which focuses on typical frame configurations. 
Although a direct comparison between codes can only be reliable if it involves the full design procedure, the reference $q$ factors in EC8 appear generally lower than $R$ values in US provisions for similar frame configurations as depicted in Table 5.1. It is also important to note that the same force-based behaviour factors $(q)$ are typically proposed as displacement amplification factors $\left(q_{d}\right)$ in EC8. This is not the case in US provisions where specific seismic drift amplification factors $\left(C_{d}\right)$ are suggested; these values appear to be generally lower than the corresponding $\mathrm{R}$ factors for most frame types. Recent research studies on inelastic seismic drift demands in moment frames (Kumar et al. 2013; Elghazouli et al. 2014) suggest that the EC8 approach is generally over-conservative compared to the US provisions in most cases, and improved prediction methods which account for earthquake characteristics are proposed.

It is also noteworthy that US provisions include the use of a 'system overstrength' parameter $\left(\Omega_{\mathrm{o}}\right.$, typically $\left.2.0-3.0\right)$ as opposed to determining the level of over-strength within the capacity design procedures in the case of EC8. Other notable differences include the relatively low $q$ assigned to $\mathrm{V}$-braced frames in EC8, in contrast with the US provisions which adopt the same $R$ values used for conventional concentric bracing. To this end, there seems to be a need to improve the guidance provided in EC8 on behaviour factors, particularly for braced and dual frames, and to extend it to other forms such as 'zipper' and 'buckling restrained' configurations.

\subsection{Local Ductility}

EC8 explicitly stipulates three ductility classes, namely DCL, DCM and DCH referring to low, medium and high dissipative structural behaviour, respectively. For DCL, global elastic analysis can be adopted alongside non-seismic detailing. The recommended reference ' $q$ ' factor for DCL is 1.5-2.0. In contrast, structures in DCM and DCH need to satisfy specific requirements primarily related to ensuring sufficient ductility in the main dissipative zones. The application of a behaviour factor larger than 1.5-2.0 must be coupled with sufficient local ductility within the critical dissipative zones. For buildings which are not seismically isolated or incorporating effective dissipation devices, design to DCL is only recommended for low seismicity areas. It should be noted however that this recommendation can create difficulties in practice (ECCS 2013), particularly for special or complex structures. Although suggesting the use of DCM or DCH for moderate and high seismicity often offers an efficient approach to providing ductility reserve against uncertainties in seismic action, achieving a similar level of reliability could be envisaged through the provision of appropriate levels of over-strength, possibly coupled with simple inherent ductility provisions where necessary. 


\subsubsection{Steel Sections}

For steel elements in compression or bending, local ductility is ensured in EC8 by restricting the width-to-thickness $(\mathrm{c} / \mathrm{t}$ or $\mathrm{b} / \mathrm{t}$ ) ratios within the section to avoid local buckling and hence reduce the susceptibility to low cycle fatigue and fracture. The classification used in EC3 (Eurocode 32005 ) is adopted but with restrictions related to the value of the $q$ factor (DCM: Class 1, 2, 3 for $1.5<q \leq 2.0$, or Class 1,2 for $2.0<q \leq 4$; DCH: Class 1 for $q>4$ ).

Comparison between width-to-thickness limits in EC8 and AISC reveals some notable differences (Elghazouli 2010). Figure 5.1, compares the 'seismically-compact' limits $\left(\lambda_{\mathrm{ps}}\right)$ in AISC with Class 1 width-to-thickness requirements in EC3/EC8. Whilst the limits for flange outstands in compression are virtually identical, there are significant differences for circular (CHS) and rectangular (RHS) hollow sections, which are commonly used for bracing and column members. For both CHS and RHS, the limits of $\lambda_{\text {ps }}$ are significantly more stringent than Class 1, with the limit being nearly double in the case of RHS. Although the $q$ factors for framed systems are generally lower than $R$ factors in most cases, the differences in cross-section limits in the two codes are significantly more severe. This suggests that tubular members satisfying the requirements of EC8 are likely to be more vulnerable to local buckling and ensuing fracture in comparison with those designed to AISC. There seems to be a need for further assessment of the adequacy of various EC3 section classes in satisfying the cyclic demands imposed under realistic seismic conditions.

\subsubsection{Composite Sections}

EC8 refers to three general design concepts for composite steel/concrete structures: (i) Concept $a$ : low-dissipative structural behaviour - which refers to DCL in the same manner as in steel structures; (ii) Concept $b$ : dissipative structural behaviour with composite dissipative zones for which DCM and DCH design can be adopted with additional rules to satisfy ductility and capacity design requirements; Concept $c$ : dissipative structural behaviour with steel dissipative zones, and therefore specific measures are stipulated to prevent the contribution of concrete under seismic conditions; in this case, critical zones are designed as steel, although other 'nonseismic' design situations may consider composite action to Eurocode 4 (2004).

For dissipative composite zones (i.e. Concept $b$ ), the beneficial presence of the concrete parts in delaying local buckling of the steel components is accounted for by relaxing the width-to-thickness ratio as indicated in Table 5.2 which is adapted from EC8. In the table, partially encased elements refer to sections in which concrete is placed between the flanges of I or $\mathrm{H}$ sections, whilst fully encased elements are those in which all the steel section is covered with concrete. The crosssection limit $c / t_{f}$ refers to the slenderness of the flange outstand of length $c$ and 


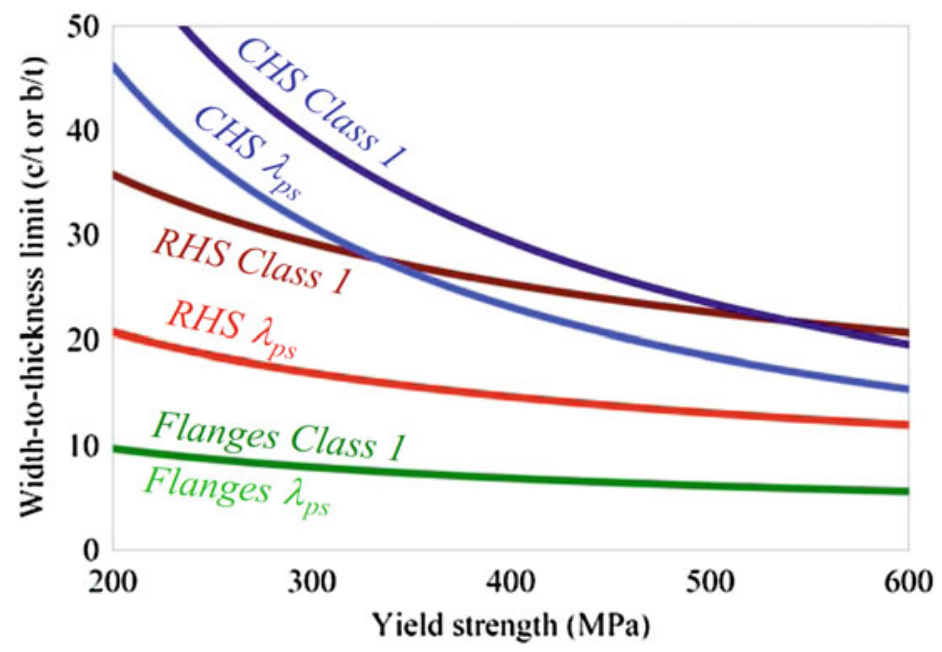

Fig. 5.1 Comparison of width-to-thickness requirements for high ductility

Table 5.2 Cross-section limits for composite sections in EC8

\begin{tabular}{l|l|l|l}
\hline Ductility classes & $\begin{array}{l}\text { Partially or fully } \\
\text { encased sections }\end{array}$ & $\begin{array}{l}\text { Concrete filled } \\
\text { rectangular sections }\end{array}$ & $\begin{array}{l}\text { Concrete filled } \\
\text { circular sections }\end{array}$ \\
\hline $\begin{array}{l}\text { DCM } \\
(\mathrm{q} \leq 1.5-2.0)\end{array}$ & $\mathrm{c} / \mathrm{t}_{\mathrm{f}} \leq 20 \sqrt{235 / f_{y}}$ & $\mathrm{~h} / \mathrm{t} \leq 52 \sqrt{235 / f_{y}}$ & $\mathrm{~d} / \mathrm{t} \leq 90\left(235 / f_{y}\right)$ \\
\hline $\begin{array}{l}\mathrm{DCM} \\
(1.5-2.0 \leq \mathrm{q} \leq 4.0)\end{array}$ & $\mathrm{c} / \mathrm{t}_{\mathrm{f}} \leq 14 \sqrt{235 / f_{y}}$ & $\mathrm{~h} / \mathrm{t} \leq 38 \sqrt{235 / f_{y}}$ & $\mathrm{~d} / \mathrm{t} \leq 85\left(235 / f_{y}\right)$ \\
\hline $\mathrm{DCM}(\mathrm{q}>4.0)$ & $\mathrm{c} / \mathrm{t}_{\mathrm{f}} \leq 9 \sqrt{235 / f_{y}}$ & $\mathrm{~h} / \mathrm{t} \leq 24 \sqrt{235 / f_{y}}$ & $\mathrm{~d} / \mathrm{t} \leq 80\left(235 / f_{y}\right)$ \\
\hline
\end{tabular}

thickness $t_{f}$. The limits in hollow rectangular steel sections filled with concrete are represented in terms of $h / t$, which is the ratio between the maximum external dimension $h$ and the tube thickness $t$. Similarly, for filled circular sections, $d / t$ is the ratio between the external diameter $d$ and the tube thickness $t$. As in the case of steel sections, notable differences also exist between the limits in EC8 for composite sections when compared with equivalent US provisions. Also, it should be noted that the limits in Table 5.2 for partially encased sections (Elghazouli and Treadway 2008) may be relaxed even further if special additional details are provided to delay or inhibit local buckling as indicated in Fig. 5.2 (Elghazouli 2009).

For beams connected to slabs, a number of requirements are stipulated in EC8 in order to ensure satisfactory performance as dissipative composite elements (i.e. for Concept $b$ ). These requirements comprise several criteria including those related to the degree of shear connection, ductility of the cross-section and effective width assumed for the slab. As in other codes, EC8 aims to ensure ductile behaviour in composite sections by limiting the maximum compressive strain that can be imposed on concrete in the sagging moment regions of the dissipative zones. This 

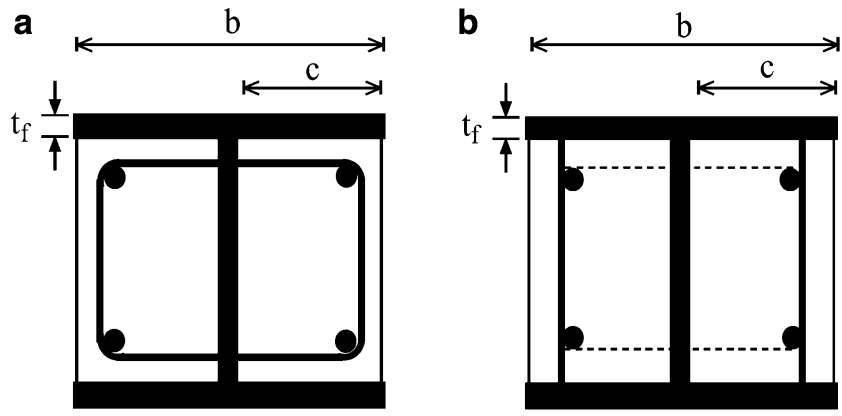

Fig. 5.2 Partially encased composite sections: (a) conventional, (b) with welded bars

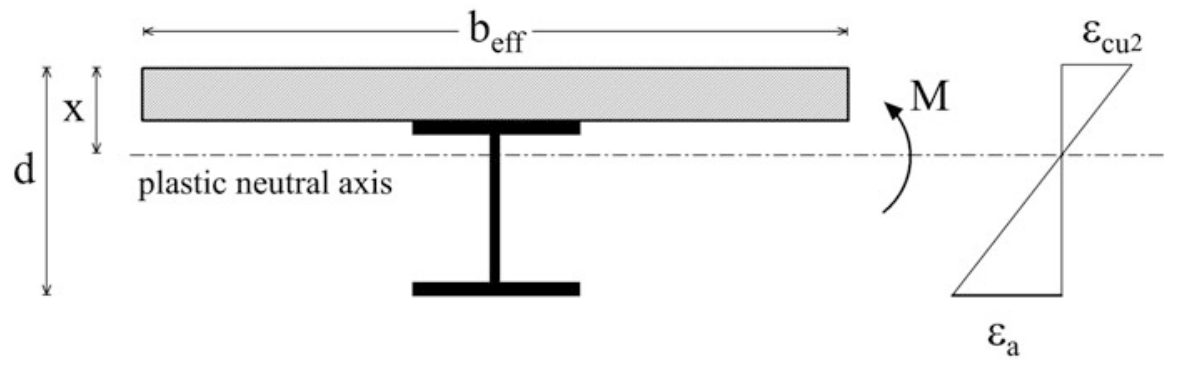

Fig. 5.3 Ductility and effective width of composite beam sections

is achieved by limiting the maximum ratio of $x / d$, as shown in Fig. 5.3. Limiting ratios are provided as a function of the ductility class (DCM or DCH) and yield strength of steel $\left(f_{y}\right)$. Close observation suggests that these limits are derived based on assumed values for $\varepsilon_{c u 2}$ of $0.25 \%$ and $\varepsilon_{a}$ of $q \times \varepsilon_{y}$, where $\varepsilon_{y}$ is the yield strain of steel.

For dissipative zones of composite beams within moment frames, EC8 requires the inclusion of 'seismic bars' in the slab at the beam-to-column connection region. The objective is to incorporate ductile reinforcement detailing to ensure favourable dissipative behaviour in the composite beams. The detailed rules are given in Annex C of Part 1 and include reference to possible mechanisms of force transfer in the beam-to-column connection region of the slab. The provisions are largely based on background European research involving detailed analytical and experimental studies (Plumier et al. 1998). It should be noted that Annex C of the code only applies to frames with rigid connections in which the plastic hinges form in the beams; the provisions in the annex are not intended, and have not been validated, for cases with partial strength beam-to-column connections.

Another important consideration related to composite beams is the extent of the effective width $b_{\text {eff }}$ assumed for the slab, as indicated also in Fig. 5.3. EC8 includes two tables for determining the effective width. These values are based on the condition that the slab reinforcement is detailed according to the provisions of Annex C since the same background studies (Plumier et al. 1998; Doneux and 
Plumier 1999) were used for this purpose. The first table gives values for negative (hogging) and positive (sagging) moments for use in establishing the second moment of area for elastic analysis. These values vary from zero to $10 \%$ of the beam span depending on the location (interior or exterior column), the direction of moment (negative or positive) and existence of transverse beams (present or not present). On the other hand, the second table in the code provides values for use in the evaluation of the plastic moment resistance. The values in this case are as high as twice those suggested for elastic analysis. They vary from zero to $20 \%$ of the beam span depending on the location (interior or exterior column), the sign of moment (negative or positive), existence of transverse beams (present or not present), condition of seismic reinforcement, and in some cases on the width and depth of the column cross-section. Clearly, design cases other than the seismic situation would require the adoption of the effective width values stipulated in EC4. Therefore, the designer may be faced with a number of values to consider for various scenarios. Nevertheless, since the sensitivity of the results to these variations may not be significant (depending on the design check at hand), some pragmatism in using these provisions appears to be warranted. Detailed research studies (Castro et al. 2007) indicate that the effective width is mostly related to the full slab width, although it also depends on a number of other parameters such as the slab thickness, beam span and boundary conditions.

\subsection{Capacity Design Requirements}

\subsubsection{Moment Frames}

As in other seismic codes, EC8 aims to satisfy the 'weak beam/strong column' concept in moment frames, with plastic hinges allowed at the base of the frame, at the top floor of multi-storey frames and for single-storey frames. To obtain ductile plastic hinges in the beams, checks are made that the full plastic moment resistance and rotation are not reduced by coexisting compression and shear forces. To satisfy capacity design, columns should be verified for the most unfavourable combination of bending moments $M_{E d}$ and axial forces $N_{E d}$ (obtained from $M_{E d}=M_{E d, G}$ $+1.1 \gamma_{o v} \Omega M_{E d, E}$, and similarly for axial loads), where $\Omega$ is the minimum overstrength in the connected beams $\left(\Omega_{i}=M_{p l, R d} / M_{E d, i}\right)$. The parameters $M_{E d, G}$ and $M_{E d, E}$ are the bending moments in the seismic design situation due to the gravity loads and lateral earthquake forces, respectively, as shown in Fig. 5.4 (Elghazouli 2009).

The beam over-strength parameter $\left(\Omega=M_{p l, R d} / M_{E d}\right)$ as adopted in EC8 involves a major approximation as it does not account accurately for the influence of gravity loads on the behaviour (Elghazouli 2010). This issue becomes particularly pronounced in gravity-dominated frames (i.e. with large beam spans) or in low-rise configurations (since the initial column sizes are relatively small), in which the 


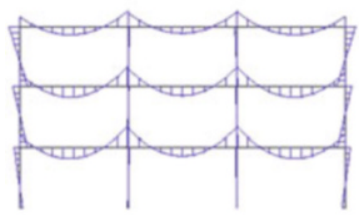

Gravity loading $\left(M_{E d, G}\right)$

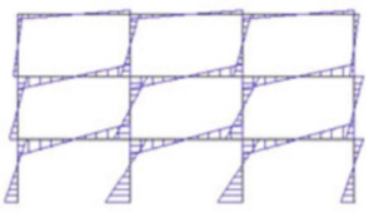

Lateral loading $\left(M_{E d, E}\right)$

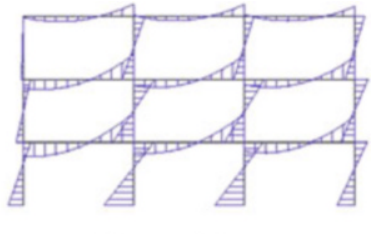

$M_{E d, G}+M_{E d, E}$

Fig. 5.4 Moment action under gravity and lateral components in the sesimic situation

beam over-strength may be significantly underestimated. The extent of the problem depends on the unclear interpretation of the code and whether $\Omega$ is used in isolation or in combination with an additional capacity design criterion based on a limiting ratio of 1.3 on the column-to-beam capacity. It is also important to note that whilst codes aim to achieve a 'weak-beam/strong-column' behaviour, some column hinging is often unavoidable. In the inelastic range, points of contra-flexure in members change and consequently the distribution of moments vary considerably from idealised conditions assumed in design. The benefit of meeting code requirements is to obtain relatively strong columns such that beam rather than column yielding dominates over several stories, hence achieving adequate overall performance.

The above-noted issue becomes more significant in composite moment frames where relatively large spans are typical. Detailed studies on composite frames (Elghazouli et al. 2008) indicate that design to EC8 can result in significant column hinging. Full beam hinging is also significantly hampered by the difference between the sagging and hogging moment capacities in composite sections. Another uncertainty in composite moment frames is related to the effective slab width as discussed before. Whilst US provisions employ the same approaches used in non-seismic design, EC8 suggests more involved procedures for seismic design in which this width varies depending on the direction of moment, location of beam, and whether the check is for resistance or capacity design. This adds to the complexity of the design and can have a notable influence on capacity design procedures. To this end, it is important to note that the dissipative zones at the beam ends of composite moment frames can be considered as steel-only sections in EC8 (i.e. following Concept c). To achieve this, the slab needs to be 'totally disconnected' from the steel members in a circular zone with a diameter of at least $2 b_{\text {eff }}$ around the columns, with $b_{\text {eff }}$ determined on the basis of the larger effective width of the connected beams. This 'total disconnection' also implies that there is no contact between the slab and the sides of any vertical element such as the columns, shear connectors, connecting plates, corrugated flange, etc.

The above consideration, of disregarding the composite action and designing for steel-only dissipative zones, can be convenient in practical design. Clearly, two $E I$ values for the beams need to be accounted for in the analysis: composite in the middle and steel at the ends. The beams are composite in the middle, hence providing enhanced stiffness and capacity under gravity loading conditions. On the other hand, in the seismic situation, the use of steel dissipative zones avoids the 


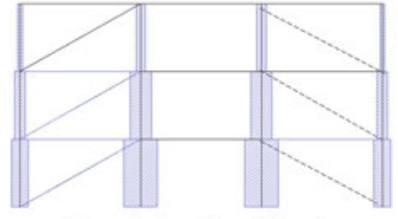

Gravity loading $\left(N_{E d, G}\right)$

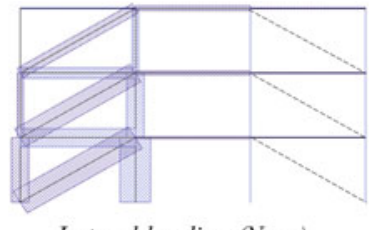

Lateral loading $\left(N_{E d, E}\right)$

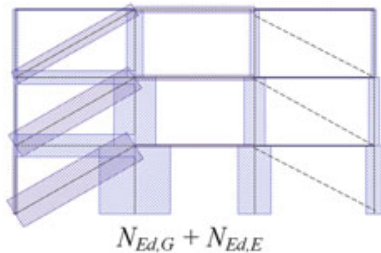

$N_{E d, G}+N_{E d \cdot E}$

Fig. 5.5 Axial action under gravity and lateral components in the seismic situation

need for detailed considerations in the slab, including those related to seismic rebars, effective width and ductility criteria associated with composite dissipative sections. This consideration also implies that the connections would be designed on the plastic capacity of the steel beams only. Additionally, the columns need to be capacity designed for the plastic resistance of steel instead of composite beam sections, which avoids over-sizing of the column members.

\subsubsection{Braced Frames}

Whilst for moment frames, the dissipative zones may be steel or composite, the dissipative zones in braced frames are typically only allowed to be in steel according to EC8. In other words, the diagonal braces in concentrically braced frames, and the bending/shear links in eccentrically braced frames, should typically be designed and detailed such that they behave as steel dissipative zones. This limitation is adopted in the code as a consequence of the uncertainty associated with determining the actual capacity and ductility properties of composite steel/concrete elements in these configurations. As a result, the design of composite braced frames follows very closely those specified for steel, an issue which merits further assessment and development.

Capacity design of concentrically braced frames in EC8 is based on ensuring yielding of the diagonals before yielding or buckling of the beams or columns and before failure of the connections. Due to buckling of the compression braces, tension braces are considered to be the main ductile members, except in $\mathrm{V}$ and inverted- $\mathrm{V}$ configurations. According to EC8, columns and beams should be capacity designed for the seismic combination actions. The design resistance of the beam or column under consideration $N_{E d}\left(M_{E d}\right)$ is determined (i.e. $N_{E d,}\left(M_{E d}\right) \geq N_{E d, G}$ $+1.1 \gamma_{o v} \Omega N_{E d} E$ ) with due account of the interaction with the bending moment $M_{E d}$, where $N_{E d, G}$ and $N_{E d, E}$, are the axial loads due to gravity and lateral actions, respectively, in the seismic design situation, as illustrated in Fig. 5.5 (Elghazouli 2009); $\Omega$ is the minimum value of axial brace over-strength over all the diagonals of the frame and $\gamma_{\mathrm{ov}}$ is the material over-strength. However, $\Omega$ of each diagonal should not differ from the minimum value by more than $25 \%$ in order to ensure reasonable distribution of ductility. It is worth noting that unlike in moment frames, gravity 


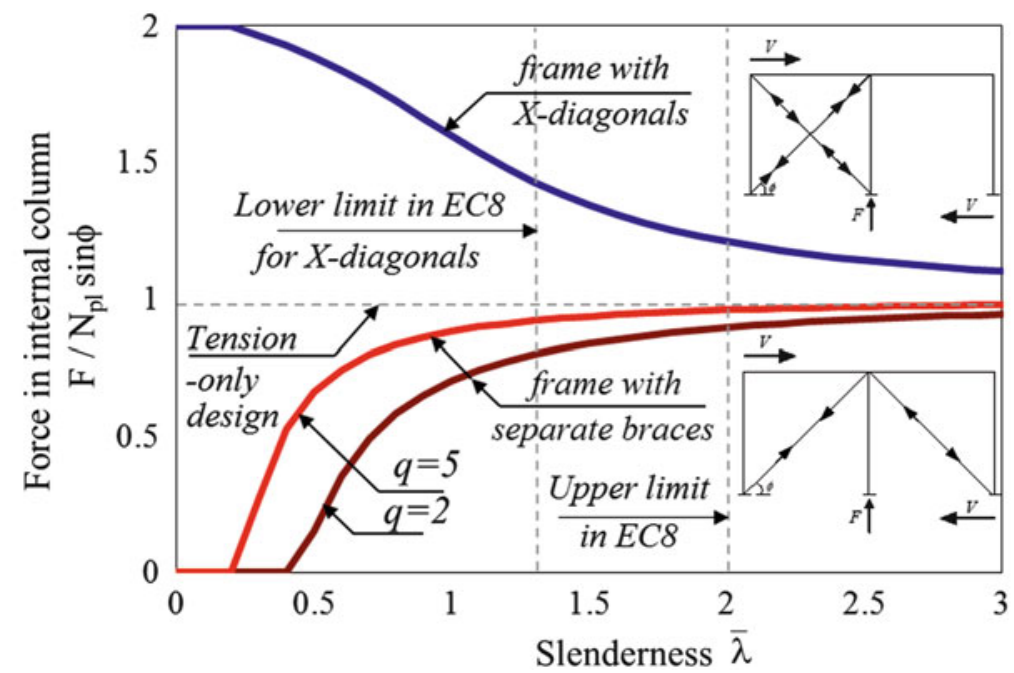

Fig. 5.6 Forces developing in columns of concentrically braced frames

loading does not normally have an influence on the accuracy of $\Omega$. It should also be noted that the $25 \%$ limit can result in difficulties in practical design; it can be shown (Elghazouli 2010) that this limit can be relaxed or even removed if measures related to column continuity and stiffness are incorporated in design.

As mentioned previously, US provisions (AISC341 2010) for braced frames differ from those in EC8 in terms of the $R$ factors recommended as well as crosssection limits for some section types. However, the most significant difference is related to the treatment of the brace buckling in compression which may lead to notably dissimilar seismic behaviour depending mainly on the slenderness of the braces. This has been examined in detail in recent studies (Elghazouli 2010), and has significant implications on the frame over-strength as well as on the applied forces and ductility demand imposed on various frame components.

As expected, in the design of the diagonal members in concentrically braced frames, the non-dimensional slenderness $\bar{\lambda}$ used in EC3 plays an important role in the behaviour (Elghazouli 2003). In earlier versions of EC8, an upper limit of 1.5 was proposed to prevent elastic buckling. However, further modifications have been made in subsequent versions of EC8 and the upper limit has been revised to a value of 2.0 which results in a more efficient design. On the other hand, in frames with X-diagonal braces, EC8 stipulates that $\bar{\lambda}$ should be between 1.3 and 2.0. The lower limit is specified in order to avoid overloading columns in the pre-buckling stage of diagonals. Satisfying this lower limit can however result in significant difficulties in practical design (Elghazouli 2009). It would be more practical to avoid placing such limits, yet ensure that forces applied on components other than the braces are based on equilibrium at the joints, with due account of the relevant actions in compression. Figure 5.6 illustrates, for example, the compression force $F$ (normalised by $N_{p l} \sin \phi$ ) developing in a column of $\mathrm{X}$ and decoupled brace 
configurations (Elghazouli 2010), where $N_{p l}$ is the axial plastic capacity of the brace cross-section and $\phi$ is the brace angle. These actions can be based on the initial buckling resistance $\left(N_{b}\right)$ or the post-buckling reserve capacity $\left(N_{p b}\right)$ depending on the frame configuration and design situation. Based on available experimental results (Goggins et al. 2005; Elghazouli et al. 2005), a realistic prediction of $N_{p b}$ can be proposed (Elghazouli 2010) accounting for brace slenderness as well as expected levels of ductility.

\subsubsection{Material Considerations}

In addition to conforming to the requirements of EC3 and EC4, EC8 stipulates further criteria related to structural steel, connection components, and reinforcement types as well as lower and upper bounds for concrete strength, amongst others. A key consideration is determining a realistic value for the over-strength of steel material $\left(\gamma_{o v}\right)$ for use in capacity design checks. A number of conditions are given in EC8 (Elghazouli 2009), but the suggested default value of 1.25 is typically adopted in practice. It is however recognised (ECCS 2013) that the level of over-strength varies significantly depending on the type and grade of steel, with the over-strength expected to be more pronounced in lower grades. As a consequence, US codes (AISC341 2010) adopt factors varying between 1.1 and 1.6, depending on the type and grade of steel. Some National Annexes to EC8 also already suggest a deviation from the recommended value of 1.25 as a function of the steel grade. Another solution would be to produce seismic steel grades with specified upper bound strength, as adopted in Japan, although this may not be practical for European manufacturers. Overall, there seems to be a need for more reliable guidance in EC8 on the levels and sources of over-strength that should be adopted in practice. Another area that requires clarification and development in EC3 and EC8 is related to the steel material toughness for application in seismic design (ECCS 2013), although this has been addressed in the National Annexes of several European countries. Specific guidance appears to be needed particularly in relation to reference temperatures and strain rates that would be appropriate to employ in seismic design situations.

\subsection{Lateral Over-Strength}

An important factor influencing seismic response is the over-strength exhibited by the structure. There are several sources that can introduce over-strength, such as material effects caused by a higher yield stress compared to the characteristic value as discussed in the previous section, or size effects due to the selection of members from standard lists, as in those used for steel sections. Additional factors include contribution of non-structural elements, or increase in member sizes due to other 


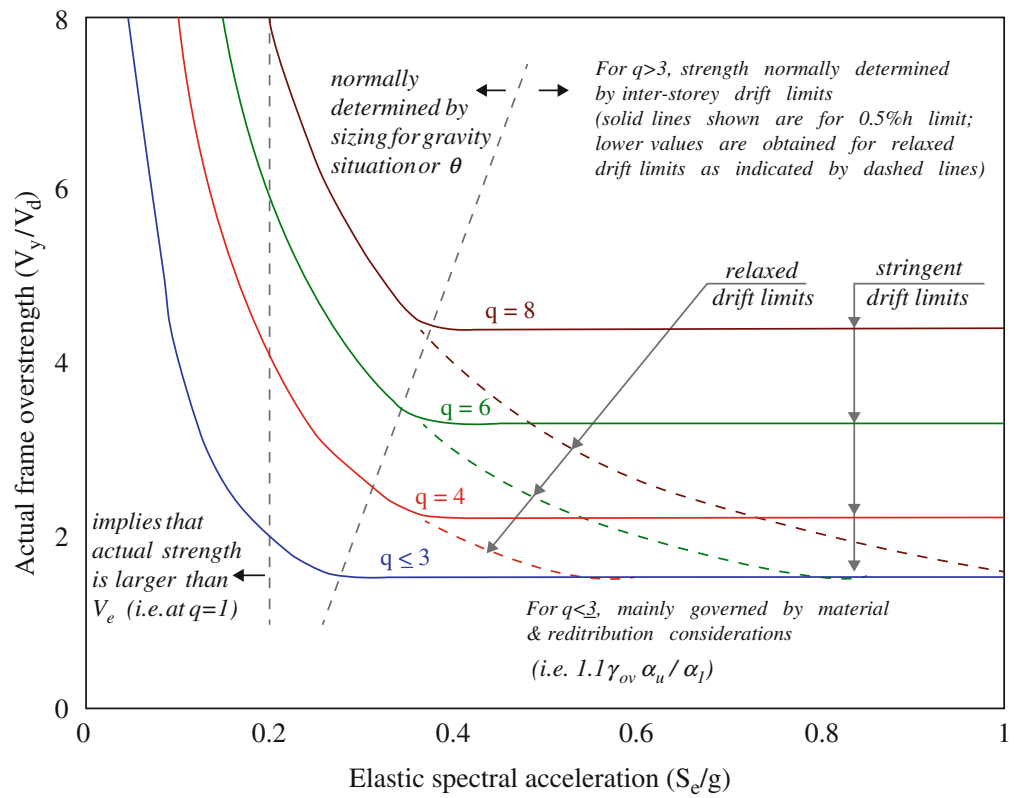

Fig. 5.7 Expected levels of lateral over-strength in moment frames

load cases or architectural considerations. Most notably, over-strength is often a direct consequence of the application of drift related requirements or inherent idealisations and simplifications within the design approaches and procedures.

\subsubsection{Stability and Drift Implications}

It can be shown that, in comparison with North American and other international provisions, drift-related requirements in EC8 are significantly more stringent (Elghazouli 2010). This is particularly pronounced in case of the stability coefficient $\theta$, which is a criterion that warrants further detailed consideration. As a consequence of the stern drift and stability requirements and the relative sensitivity of framed structures, particularly moment frames, to these effects, they can often govern the design leading to considerable over-strength, especially if a large behaviour factor is assumed. This over-strength (represented as the ratio of the actual base shear $V_{y}$ to the design value $V_{d}$ ) is also a function of the normalised elastic spectral acceleration $\left(S_{a} / g\right)$ and gravity design, as illustrated in Fig. 5.7 (Elghazouli 2010).

Whereas the presence of over-strength reduces the ductility demand in dissipative zones, it also affects forces imposed on frame and foundation elements. A rational application of capacity design necessitates a realistic assessment of lateral 


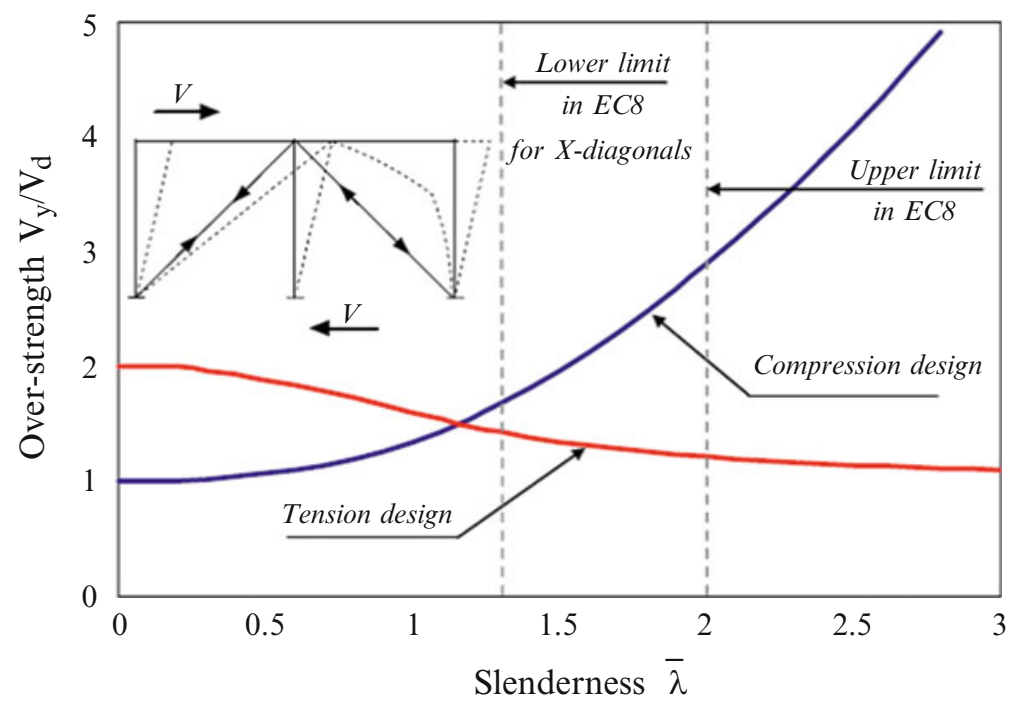

Fig. 5.8 Lateral frame over-strength arising from tension and compression design

capacity after the satisfaction of all provisions, followed by a re-evaluation of global over-strength and the required ' $q$ '. Although high ' $q$ ' factors are allowed for moment frames, in recognition of their ductility and energy dissipation capabilities, it should be noted that such a choice is often unnecessary and could lead to undesirable effects.

\subsubsection{Influence of Design Idealisations}

As noted above, simplifications in the design procedure can result directly in considerable levels of structural over-strength. A most significant source of overstrength in concentrically braced frames arises from the simplification associated with the treatment of brace buckling in compression. To enable the use of linear elastic analysis tools, commonly employed in design practice, two different approaches are normally adopted in design methods. Whereas several codes, such as US provisions (AISC341 2010), base the design strength on the brace buckling capacity in compression (with a few exceptions), European provisions are largely based on the brace plastic capacity in tension (except for $\mathrm{V}$ and inverted-V configurations).

Whilst both the tension and compression based approaches lead to frame overstrength, they have directly opposite trends with the respect to the brace slenderness (Elghazouli 2003), as illustrated in Fig. 5.8. The over-strength arising from the tension-based idealisation is insignificant for relatively slender braces but approaches a factor of two for relatively stocky braces. In contrast, the over- 
strength arising from the compression design is insignificant for stocky members but increases steadily with the slenderness ratio. As noted previously, it is important to quantify the level of over-strength in a frame and assess the actual forces sustained by the braces in compression. Depending on the specific design situation and frame configuration, it may be necessary to estimate either the maximum or minimum forces attained in compression members in a more realistic manner as opposed to the idealised approaches currently adopted in seismic codes.

\subsection{Connection Design}

\subsubsection{Steel Moment Connections}

Steel moment frames have traditionally been designed with rigid full-strength connections, usually of fully-welded or hybrid welded/bolted configuration. Typical design provisions ensured that connections are provided with sufficient overstrength such that dissipative zones occur mainly in the beams. However, the reliability of commonly-used forms of full-strength beam-to-column connection has come under question following poor performance in large seismic events, particularly in Northridge and Kobe earthquakes (SAC 1995). The extent and repetitive nature of damage observed in several types of welded and hybrid connections have directed considerable research effort not only to repair methods for existing structures but also to alternative connection configurations to be incorporated in new designs.

Observed seismic damage to welded and hybrid connections was attributed to several factors including defects associated with weld and steel materials, welding procedures, stress concentration, high rotational demands, scale effects, as well as the possible influence of strain levels and rates (FEMA 2000). In addition to the concerted effort dedicated to improving seismic design regulations for new construction, several proposals have been forwarded for the upgrading of existing connections. As shown schematically in Fig. 5.9 (Elghazouli 2009), this may be carried out by strengthening of the connection through haunches, cover or side plates, or other means. Alternatively, it can be achieved by weakening of the beam by trimming the flanges (i.e. reduced beam section 'RBS' or 'dog-bone' connections), perforating the flanges, or by reducing stress concentrations through slots in beam webs, enlarged access holes, etc. In general, the design can be based on either prequalified connections or on prototype tests. Prequalified connections have been proposed in the US (AISC358 2010), and a similar European activity is currently underway. It should be noted however that most prequalification activities have been focusing on connections to open section columns, with comparatively less attention given to connections to tubular columns (Elghazouli and Packer 2014). 

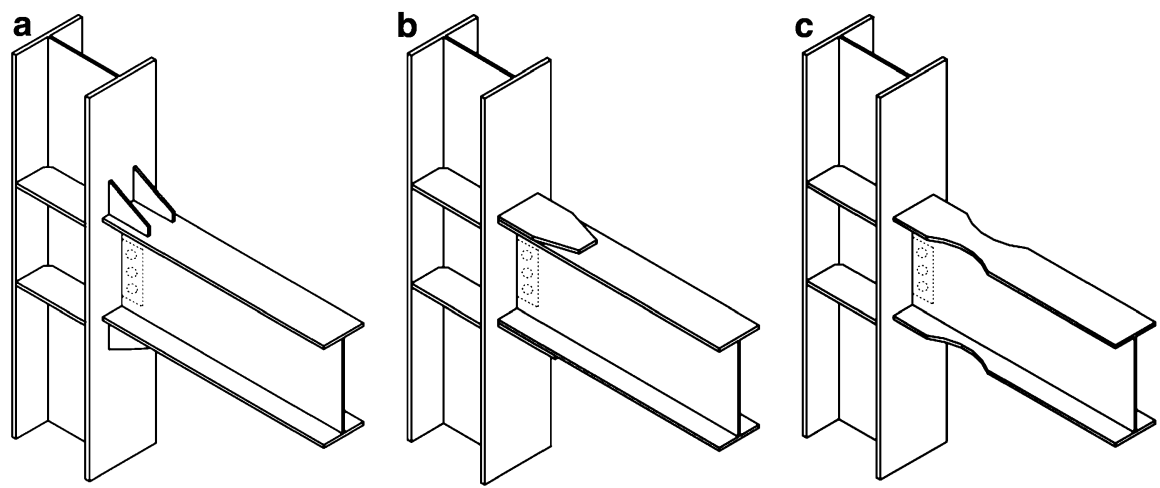

Fig. 5.9 Examples of modified moment beam-to-column connection configurations: (a) with haunches, (b) with cover plates; (c) reduced beam section

Another important aspect of connection behaviour is related to the influence of the column panel zone. This has direct implications on the ductility of dissipative zones as well as on the overall frame performance. Recent research studies (Castro et al. 2008), involved the development of realistic modelling approaches for panel zones within moment frames as well as assessment of current design procedures. One important issue is related to the treatment of the two yield points corresponding to the onset of plasticity in the column web and surrounding components, respectively. Another key design consideration is concerned with balancing the extent of plasticity between the panel zone and the connected beams, an issue which can be significantly affected by the level of gravity applied on the beams. On the one hand, allowing a degree of yielding in the panel reduces the plastic hinge rotations in the beams yet, on the other hand, relatively weak panel zone designs can result in excessive distortional demands which can cause unreliable behaviour of other connection components particularly in the welds. The approaches used in European guidance, through the combined provisions of EC3 or EC4 with EC8, appear to lead to significantly different design in comparison with that adopted in US provisions, an issue which requires further examination and development.

Bolted connections, which can be designed as rigid or semi-rigid, can alleviate many of the drawbacks of welded forms (Elghazouli 2009). However, the guidance for semi-rigid bolted connections varies in detail between US and EC8 procedures. In AISC, partially-restrained (PR) connections are not permitted for intermediate or special moment frames connections. They can only be used in ordinary moment frames, provided the nominal connection strength is not less than $50 \%$ of the plastic moment capacity of the beam, and the stiffness, strength and deformation capacity of the PR moment connections are considered in the design including the effect on overall frame stability. On the other hand, EC8 permits in principle the use of partial strength (i.e. dissipative) connections in primary lateral load-resisting systems provided that: (i) all connections have rotation capacity consistent with global deformations, (ii) members framing into connections are stable at the ultimate limit 
state, and (iii) connection deformation is accounted for through nonlinear analysis. Unlike in AISC, there is no limit given in EC8 on the minimum moment ratio, nor on the use with different ductility classes. Dissipative connections should satisfy the rotational demand implied for plastic hinge zones, irrespective of whether the connections are partial or full strength; these are specified as 25 and $35 \mathrm{mrad}$ for DCM and DCH, respectively, which are broadly similar to the demands in IMF and SMF in AISC 341 (total drift of 0.02 and $0.04 \mathrm{rad}$, for IMF and SMF, respectively).

\subsubsection{Composite Moment Connections}

As discussed previously, EC8 permits three general design concepts for composite structures (low dissipative behaviour, dissipative composite zones or dissipative steel zones). On the other hand, AISC refers to specific composite systems as indicated in Table 5.1 (e.g. C-OMF, C-IMF, C-SMF). In principle, this classification applies to systems consisting of composite or reinforced concrete columns and structural steel, concrete-encased composite or composite beams. The use of PR connections (C-PRMF) is included, and is applicable to moment frames that consist of structural steel columns and composite beams that are connected with partially restrained (PR) moment connections. Similar to PR steel connections, they should have strengths of at least $0.5 \mathrm{M}_{\mathrm{p}}$ but additionally should exhibit a rotation capacity of at least 0.02 rad. It should be noted that, as mentioned previously, Annex C in EC8 for the detailing of slabs only applies to frames with rigid connections in which the plastic hinges form in the beams. However, guidance on the detailing of composite joints using partial strength connections are addressed in the commentary of AISC 341 for C-PRMF systems.

The use of composite connections can often simplify some of the challenges associated with traditional steel and concrete construction, such as minimizing field welding and anchorage requirements. Given the many alternative configurations of composite structures and connections, there are few standard details for connections in composite construction. In most composite structures built to date, engineers have designed connections using basic mechanics, equilibrium models (e.g. classical beam-column, truss analogy, strut and tie, etc.), existing standards for steel and concrete construction, test data, and good judgment. As noted above, however, engineers do face inherent complexities and uncertainties when dealing with composite dissipative connections, which can often counterbalance the merits of this type of construction when choosing the structural form. In this context, the 'total disconnection' approach permitted in EC8 (i.e. Concept c) offers a practical alternative in order to use standard or prequalified steel-only beam-to-column connections. This status can also be achieved using North American codes provided the potential plastic hinge regions are maintained as pure steel members. A similar approach has also been recently used in hybrid flat slab-tubular column connections (Eder et al. 2012), hence enabling the use of flat slabs in conjunction with steel-only dissipative members. 


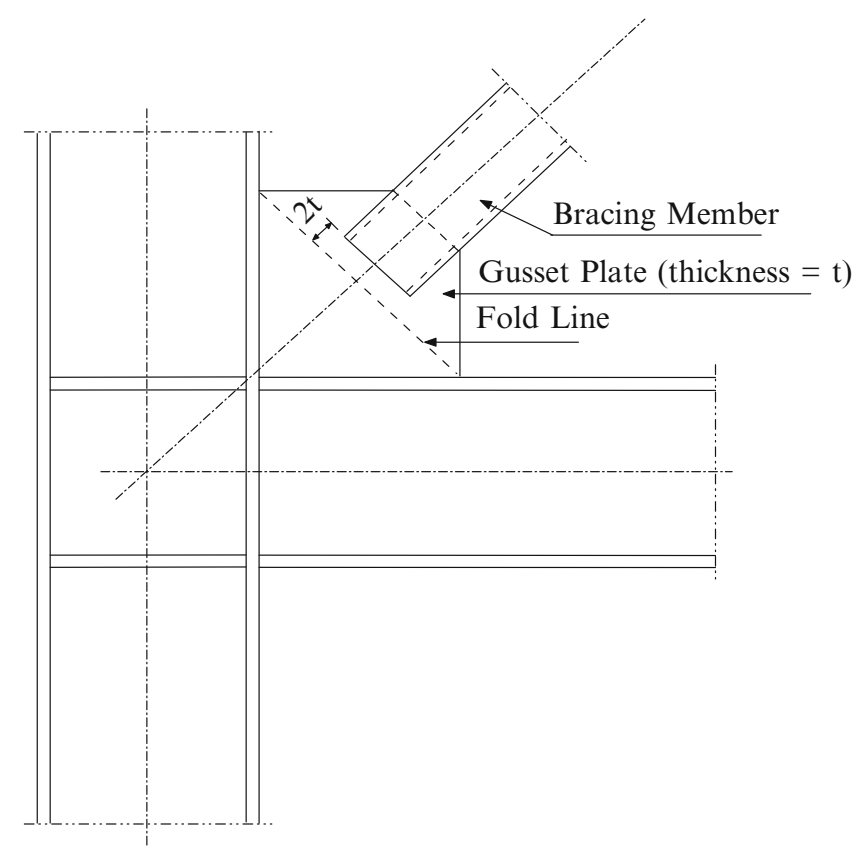

Fig. 5.10 Gusset plate connections in concentrically braced frames

\subsubsection{Bracing Connections}

Issues related to connection performance and design are clearly not only limited to moment connections, but also extend to other configurations such as connections to bracing members. Many of the failures reported in concentrically braced frames due to strong ground motion have been in the connections. In principle, bracing connections can be designed as rotationally restrained or unrestrained, provided that they can transfer the axial cyclic tension and compression effectively. The inand out-of-plane behaviour of the connection, and their influence on the beam and column performance, should be carefully considered in all cases. For example, considering gusset plate connections, as shown in Fig. 5.10 (Elghazouli 2009), satisfactory performance can be ensured by allowing the gusset plate to develop plastic rotations. This requires that that the free length between the end of the brace and the assumed line of restraint for the gusset can be sufficiently long to permit plastic rotations, yet short enough to preclude the occurrence of plate buckling prior to member buckling. Alternatively, connections with stiffness in two directions, such as crossed gusset plates, can be detailed. The performance of bracing connections, such as those involving gusset plate components, has attracted significant research interest in recent years (e.g. Lehman et al. 2008). Alternative tri-linear and nonlinear fold-line representations have been proposed and validated. A recent European research programme has also examined the performance of alternative 
forms of gusset-plate bracing connections and provided recommendations on optimum configurations for use in design (Broderick et al. 2013).

Design examples for bracing-to-gusset plate connections in concentrically and eccentrically braced frames are given in the AISC Seismic Design Manual (2012), in accordance with AISC 341 and ASCE7, and typically require many considerations and design checks. In contrast, as for moment connections, the design of connections between bracing members and beams/columns is only dealt with in a conceptual manner in EC8. Accordingly, designers can adopt details available from the literature, or based on prototype testing.

Designing bracing connections in an efficient and practical manner can be complex and time-consuming, and requires significant expertise (Elghazouli and Packer 2014). This has led to the development of 'pre-engineered' proprietary solutions using 'off-the-shelf' cast steel connections (Herion et al. 2010). A substantially more compact field-bolted connection is achieved than would otherwise be possible with typical bolted connections using splice plates. Other proprietary connections include yielding 'fuses' such as the Yielding Brace System (YBS) (Gray et al. 2014). In this case, dissipation is provided by flexural yielding of parts of the YBS while the bracing member and other frame elements remain essentially elastic. Another 'off-the-shelf' solution is also provided through Buckling Restrained Braces which, as noted before, are not currently directly addressed in EC8. It should be noted that AISC358 is limited to prequalified solutions for steel moment connections, and does not prequalify connections for braced frames. At present, 'pre-engineered' bracing connections can perhaps be treated in a comparable manner to qualification of custom seismic products which require proof testing. Overall, compared to self-designed connections, proprietary seismic connections could offer improved performance, additional quality assurance, and the potential for savings in cost and construction time.

\subsection{Concluding Remarks}

This paper highlights various issues related to the seismic design of steel and composite frames that would benefit from further assessment and code development, with particular focus on the provisions of EC8. Since the European seismic code is in general relatively clear in its implementation of the underlying capacity design principles as well as the purpose of the parameters adopted within various procedures, its rules can be readily adapted and modified based on new research findings and improved understanding of seismic behaviour.

Comparison of EC8 provisions with those in AISC in terms of structural configurations and associated behaviour factors highlights a number of issues that are worthy of further development. Several lateral resisting systems that are currently dealt with in AISC are not incorporated in EC8 including steel-truss moment frames, steel-plate walls and buckling-restrained braces. It is anticipated that these will be considered in future revisions of the code. Another notable difference is the 
relatively low $q$ assigned to V-braced frames in EC8 compared to AISC, which highlights the need for further assessment of behaviour factors particularly for braced and dual frames in EC8, and to extend it to other forms such as 'zipper' and 'buckling restrained' configurations. It is also shown that whilst EC8 typically adopts the equal-displacement approach for predicting inelastic drift, US provisions employ specific seismic drift amplification factors. It is however noted that there is a need for seismic codes to adopt improved prediction methods which account for earthquake characteristics.

In terms of local ductility, comparison of the width-to-thickness limits in EC8 and AISC reveals considerable differences, particularly in the case of rectangular and circular tubular members. Since the ductility capacity and susceptibility to fracture are directly related to the occurrence of local buckling, it seems necessary to conduct further assessment of the adequacy of Class 1 sections to satisfy the cyclic demands imposed under prevalent seismic conditions. For composite dissipative sections, the requirements in EC8 for determining the effective width and the detailing in the slab is intricate, and some pragmatism and simplification in its application may be necessary, unless the option of 'disconnection' is adopted. It is also noted that allowing DCL or modified-DCL detailing in EC8 for moderate seismicity, with an appropriate reserve capacity, may be desirable particularly for special or complex structures.

It is observed that in EC8 the capacity-design application rules for columns ignore the important influence of gravity loads on the over-strength of beams. This issue becomes particularly pronounced in gravity-dominated frames or in low-rise configurations. The extent of the problem depends on the interpretation of the code and whether $\Omega$ is used in isolation or in combination with an additional capacity design criterion based on a limiting ratio of 1.3 on the column-to-beam capacity. The above-noted issue becomes more significant in composite moment frames where relatively large spans are typical. This is also added to the problem of achieving full beam hinging in dissipative composite frames due to the difference between the sagging and hogging moment capacities in composite sections.

In order to mitigate the vulnerability of braced frames to the concentration of inelastic demand within critical storeys, EC8 introduces a $25 \%$ limit on the maximum difference in brace over-strength $\left(\Omega_{i}\right)$ within the frame. Detailed studies show that this may not eliminate the problem and can impose additional design effort and difficulties in practical design. Instead, this limit can be significantly relaxed or even removed if measures related to column continuity and stiffness are incorporated in design. Another issue related to concentrically braced frames is the lower slenderness limit of 1.3 imposed in EC8 for X-bracing, in order to limit the compression force in the brace. Satisfying this limit can result in significant difficulties in practical design. It would be more practical to avoid placing such limits, yet ensure that forces applied on components other than the braces are based on equilibrium at the joints, with due account of the relevant actions in compression. Improved procedures that account for brace slenderness as well as expected levels of ductility could be adopted. 
For the purpose of capacity design checks, it is important to determine a realistic value for the over-strength of steel material. Unlike AISC, EC8 suggests a default value of 1.25. It is recognised however that the level of over-strength varies significantly depending on the type and grade of steel, with the over-strength expected to be more pronounced in lower grades. There seems to be a need for more reliable guidance in EC8 on the levels and sources of material over-strength that should be adopted in practice. Another area that requires clarification and development in EC3 and EC8 is related to the steel material toughness for application in seismic design. Specific guidance appears to be needed particularly in relation to reference temperatures and strain rates that would be appropriate to employ in seismic design situations.

Apart from over-strength arising from the material, lateral frame over-strength can be a direct result of design idealisations or the application of drift-related criteria. A significant design idealisation in concentrically braced frames is related to the treatment of buckling of the compression braces. Whereas AISC largely bases the design strength on the brace buckling capacity in compression, EC8 adopts the brace plastic capacity in tension with few exceptions. Whilst both simplifications lead to frame over-strength, they have directly opposite trends with respect to the brace slenderness. Depending on the specific design situation and frame configuration, it may be necessary to estimate either the maximum or minimum forces attained in compression members in a more realistic manner as opposed to the idealised approaches currently adopted in seismic codes.

The other key consideration influencing lateral frame over-strength is related to drift criteria. In comparison with other seismic codes, drift and stability requirements in EC8 are significantly more stringent. As a consequence, these checks can often govern the design, leading to considerable over-strength, especially if a high ' $q$ ' is assumed. Whereas the presence of over-strength reduces the ductility demand in dissipative zones, it also affects forces imposed on frame and foundation elements. A rational application of capacity design necessitates a realistic assessment of lateral capacity after the satisfaction of all provisions, followed by a re-evaluation of global over-strength and the required ' $q$ '. Although high ' $q$ ' factors are allowed for various frame types in EC8, such a choice is often unnecessary and undesirable.

In terms of beam-to-column connections, there is clearly a need for a concerted effort to develop European guidance, in conjunction with the principles of EC8, on appropriate connection detailing using representative sections, materials and detailing practices. There is also a need for reviewing the design of column panel zones in moment frames, resulting from the combined application of the rules in EC3 and EC8. In particular, the definition of the yield point as well as the balance of plasticity between the panel and connected beams require further consideration. In general, it seems logical for future activities to promote the development of 'prequalified' or 'pre-engineered' seismic connections that satisfy the requirements of EC8, and to provide supporting design procedures and associated simplified analytical tools. These should not be limited to welded moment connections, but 
should extend to bolted rigid and semi-rigid configurations as well as joints of bracing members and link zones in braced frames.

Open Access This chapter is distributed under the terms of the Creative Commons Attribution Noncommercial License, which permits any noncommercial use, distribution, and reproduction in any medium, provided the original author(s) and source are credited.

\section{References}

AISC (2012) Seismic design manual, 2nd edn. American Institute of Steel Construction Inc., AISC, Chicago

AISC 341 (2010) Seismic provisions for structural steel buildings. ANSI/AISC 341-10 American Institute of Steel Construction Inc., AISC, Chicago

AISC 358 (2010) Prequalified connections for special and intermediate steel moment frames for seismic applications. ANSI/AISC 358-10, American Institute of Steel Construction Inc., AISC, Chicago

ASCE7 (2010) ASCE/SEI - ASCE 7-10 - minimum design loads for buildings and other structures. American Society of Civil Engineers/Structural Engineering Institute, Reston

Broderick BM, Hunt A, Mongabure P, LeMaoult A, Goggins JM, Salawdeh, S, O'Reilly G, Beg D, Moze P, Sinur F, Elghazouli AY, and Plumier A (2013) Assessment of the seismic response of concentrically-braced frames. SERIES Concluding Workshop, Earthquake Engineering Research Infrastructures, European Commissions, JRC-Ispra, Italy

Castro JM, Elghazouli AY, Izzuddin BA (2007) Assessment of effective slab widths in composite beams. J Constr Steel Res 63(10):1317-1327

Castro JM, Davila-Arbona FJ, Elghazouli AY (2008) Seismic design approaches for panel zones in steel moment frames. J Earthq Eng 12(S1):34-51

Doneux C, Plumier A (1999) Distribution of stresses in the slab of composite steel-concrete moment resistant frames submitted to earthquake action. Stahlbau 68(6):438-447

ECCS (2013) Assessment of EC8 provisions for seismic design of steel structures. In: Landolfo R (ed) European convention for constructional steelwork, Brussels

Eder MA, Vollum RL, Elghazouli AY (2012) Performance of ductile RC flat slab-to-steel column connections under cyclic loading. Eng Struct 36(1):239-257

Elghazouli AY (2003) Seismic design procedures for concentrically braced frames. Struct Build 156:381-394

Elghazouli AY (ed) (2009) Seismic design of buildings to Eurocode 8. Taylor and Francis/Spon Press, London

Elghazouli AY (2010) Assessment of European seismic design procedures for steel framed structures. Bull Earthq Eng 8(1):65-89

Elghazouli AY, Packer JA (2014) Seismic design solutions for connections to tubular members. J Steel Constr 7(2):73-83

Elghazouli AY, Treadway J (2008) Inelastic behaviour of composite members under combined bending and axial loading. J Constr Steel Res 64(9):1008-1019

Elghazouli AY, Broderick BM, Goggins J, Mouzakis H, Carydis P, Bouwkamp J, Plumier A (2005) Shake table testing of tubular steel bracing members. Struct Build 158:229-241

Elghazouli AY, Castro JM, Izzuddin BA (2008) Seismic performance of composite moment frames. Eng Struct 30(7):1802-1819

Elghazouli AY, Kumar M, Stafford PJ (2014) Prediction and optimisation of seismic drift demands incorporating strong motion frequency content. Bull Earthq Eng 12(1):255-276

Eurocode 3 (2005) Design of steel structures - Part 1.1: General rules and rules for buildings. EN 1993-1: 2005, European Committee for Standardization, CEN, Brussels 
Eurocode 4 (2004) Design of composite steel and concrete structures - Part 1.1: General rules and rules for buildings. EN 1994-1: 2004, European Committee for Standardization, CEN, Brussels

Eurocode 8 (2005) Design of structures for earthquake resistance - Part 1: General rules, seismic actions and rules for buildings. EN 1998-1: 2004, European Committee for Standardization, Brussels

FEMA (2000) Federal Emergency Management Agency. Recommended seismic design criteria for new steel moment-frame buildings. Program to reduce earthquake hazards of steel momentframe structures, FEMA-350, FEMA, Washington, DC

Goggins JM, Broderick BM, Elghazouli AY, Lucas AS (2005) Experimental cyclic response of cold-formed hollow steel bracing members. Eng Struct 27(7):977-989

Gray MG, Christopoulos C, Packer JA (2014) Cast steel yielding brace system (YBS) for concentrically braced frames: concept development and experimental validations. J Struct Eng (American Society of Civil Engineers) 140(4):pp.04013095

Herion S, de Oliveira JC, Packer JA, Christopoulos C, Gray MG (2010) Castings in tubular structures - the state of the art. Struct Build (Proceedings of the Institution of Civil Engineers) 163(SB6):403-415

Kumar M, Stafford PJ, Elghazouli AY (2013) Influence of ground motion characteristics on drift demands in steel moment frames designed to Eurocode 8. Eng Struct 52:502-517

Lehman DE, Roeder CW, Herman D, Johnson S, Kotulka B (2008) Improved seismic performance of gusset plate connections. J Struct Eng, ASCE 134(6):890-901

Plumier A, Doneux C, Bouwkamp JG, Plumier C (1998) Slab design in connection zones of composite frames. Proceedings of the 11th ECEE Conference, Paris

SAC (1995) Survey and assessment of damage to buildings affected by the Northridge Earthquake of January 17, 1994, SAC95-06, SAC Joint Venture, Sacramento 